\title{
Heparin and other anticoagulants in amniotic fluid embolism (AFE): Literature review and concept of the therapy
}

\author{
Mieczysław Uszyński ${ }^{*}$, Waldemar Uszyński \\ ${ }^{1}$ Department of Propedeutics of Medicine, Collegium Medicum in Bydgoszcz, Nicolaus Copernicus University, Toruń, Poland \\ ${ }^{2}$ Regional Hospital, Włocławek, Poland \\ Email: ${ }^{*}$ kizproped@amb.bydgoszcz.pl, wuszynski@tlen.pl
}

Received 2 July 2013; revised 1 August 2013; accepted 10 August 2013

Copyright (C) 2013 Mieczysław Uszyński, Waldemar Uszyński. This is an open access article distributed under the Creative Commons Attribution License, which permits unrestricted use, distribution, and reproduction in any medium, provided the original work is properly cited.

\begin{abstract}
Aim: The objective of this study is to review all the reported outcomes of heparin application in amniotic fluid embolism (AFE) so far and to find out why, when and how heparin or other anticoagulants should be used in AFE. Material and methods: We searched Medline (from 1969 to 2011), using two key words: 1) amniotic fluid embolism; 2) amniotic fluid embolism and heparin. The search for the former produced 1127 replies, of which 208 were case reports of AFE. In response to the other key word, there were 94 articles. We looked through all the articles, selecting those relevant for our study. Results: In the years 1969-2011, 208 AFE cases were reported. Heparin (unfractionated heparin) or low molecular weight heparin (LMWH) was applied in 20 cases $(9.6 \%)$, being the main drug in 11 cases $(5.3 \%)$ and in 6 cases as a component of spectacular treatment of AFE (surgical treatment and extracorporal membrane oxygenation). In one of these cases anithrombin (AT) with LMWH was used. In one patient heparin therapy was considered to be unsuccessful and hence recombinant plasminogen activator (rt-PA) was instituted. All the patients survived. Conclusions: 1) The attempts to use heparin in AFE could be defined as promising, although the number of treated patients is too small for conclusion; 2) The postulate to use heparin at the very onset of AFE (a bolus of 10,000 U followed by monitored intravenous infusion) has serious justification: one of the pathways of AFE is the target for heparin (coagulation pathway).
\end{abstract}

Keywords: Amniotic Fluid Embolism; Disseminated

\footnotetext{
"Corresponding author.
}

Intravascular Coagulation; Heparin; Low Molecular Weight Heparin; Antithrombin

\section{INTRODUCTION}

Amniotic fluid embolism (AFE) is a rare but serious condition, threatening the life of both mother and child. The most common cause of death of mother is cardiac arrest followed by obstetric hemorrhage with coagulation disorders. For years, the case fatality rate has been reported to reach up to $60 \%-80 \%$, and $30 \%-50 \%$ of rescued mothers and children presented with severe neurological complications. Fortunately, a more favorite trend has also been announced, e.g. in a population-based study by Abenheim et al. [1], the case fatality rate in the USA in the years 1999-2003 was much lower than that in the past (the incidence of AFE was 7.7 per 100,000 births with a case fatality rate of $21.6 \%$ ). However, the question of how to improve therapy outcome still remains open.

Recently, some novel approaches for the diagnosis and treatment of AFE have been successfully used. For instance, transesophageal echocardiography was effectively applied to diagnose the causes of pulmonary obstruction (catastrophic pulmonary vasoconstriction vs intracardiac or pulmonary artery embolus [2-4]) and establish the diagnosis of paradoxical AFE [5,6] (identification of intracardiac shunts between venous and atrial circulation in the form of a patent foramen ovale or ventricular septal defect, and identification of intracardiac thrombi). Cardiopulmonary bypass [3] or cardiopulmonary bypass surgery $[6,7]$ succeeded to rescue AFE patients who had failed to respond to standard treatment; early application of extracorporeal membrane oxygenation rescued the patient who was unresponsive to standard oxygen therapy [8], and with inhaled nitric oxide 
prompt reversal of critical hemodynamic compromise was obtained [ 9].

The conventional management of AFE can be divided into the supportive type and etiopathogenetic type. The first includes immediate delivery of the fetus (the imperative for survival of both mother and child), adequate oxygenation with $100 \%$ oxygen, use of crystalloids and colloids (no more than $1000 \mathrm{ml}$ ) to restore the blood volume, vasopressors and many other pharmaceutics if needed, as well as substitution of consumption coagulopathy with blood products (packed red blood cells, washed platelets, fresh-frozen plasma, cryoprecipitate, whole blood), the use of recombinant factor $\mathrm{X}$, and management of uterine hemorrhage, quite frequently with surgical procedures $[10,11]$.

The etiopathogenic management of AFE involves actions oriented at the inhibition of two routes of the complication: DIC pathway and leukotriene pathway, of which one can predominate [12]; the former leads to the formation of microthrombi (most frequently) and sometimes thrombi in the pulmonary artery [7] and intracardiac thrombi [6], whereas the latter causes catastrophic pulmonary vasoconstriction [3].

Pulmonary obstructions by DIC and/or pulmonary vasoconstriction are both potentially reversible conditions providing that treatment is immediate, aggressive and etiopathogenically-oriented (inhibition of both pathogenic pathways of AFE) (Figure 1). Temporary substitution of the functions of the lungs and heart is the most effective way to struggle for patient's life. Drugs such as

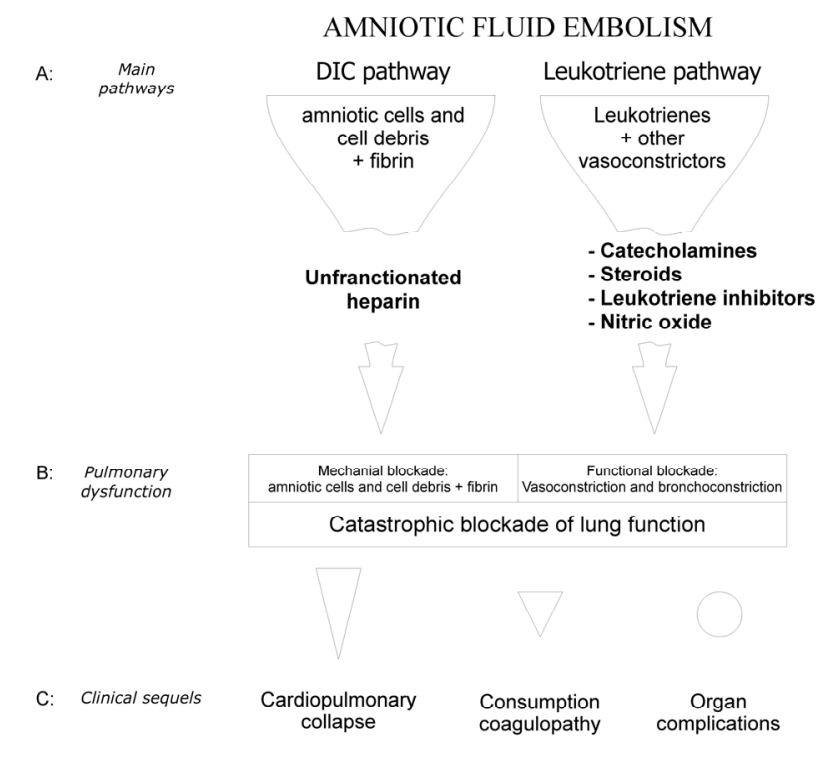

Figure 1. Illustration of the role of heparin in the treatment of amniotic fluid embolism (AFE): heparin decreases or blocks the coagulation pathway (DIC pathway), while steroids, catecholamines and leukotriene inhibitors target the leukotriene pathway. heparin, steroids and catecholamines as well as leukotriene inhibitors afford the necessary time required for the survival in critical pulmonary obstruction (time needed for spontaneous resolution of microthrombi and spontaneous decay of short half-life of pulmonary vasoconstrictors, the leukotrienes mainly (for ref. see [3]).

Optimally, all cases of AFE, and particularly the severe ones, should be treated in medical centers that employ state-of-the-art therapeutic methods (tertiary care centers). As this is rarely possible, most patients should be able to find immediate help in less-equipped centers that provide Basic Life Support (BLS) and Advances Life Support (ALS). Heparin is the drug of choice for anticoagulation in AFE due to its rapid onset of action and good efficacy, and what is essential-it inhibits the DIC pathway. Other novel anticoagulants (direct Xa and IIa inhibitors), have no such advantages [13]). Therefore, the proposal to introduce heparin to the known rescue-therapeutic algorithm of AFE, point D (drugs) [14], is justified.

In this paper, we focus on the trials of AFE management with heparin in the past and at present. We also attempt to develop our own model of therapy with heaprin.

\section{REVIEW}

\subsection{Attempts at Heparin Therapy of AFE}

The history of attempts to treat AFE with heparin goes back to the first years after the famous description of this complication by Steiner and Lusbaugh in 1941 [15]. In 1953, Reid, Weiner and Roby [16] suggested in their case report that intravascular clotting, afibrinogenemia and postpartum bleeding associated with AFE were caused by amniotic TF. In a supplementary comment attached to the paper, they claimed that administration of heparin and proteolytic inhibitors was theoretically justified. Thus, these authors can be acclaimed as protagonists of heparin and aprotonin application in AFE.

However, heparin was used only 16 years later (the first description dates back to 1969 [17]). All the authors of the casuistic descriptions were convinced that using heparin they combated the pathogenic process of DIC. Nowadays, we also believe that the use of heparin is a pathogenic treatment of AFE. On the other hand we also know that heparin only inhibits DIC and not the coexisting leucotriene pathway [11].

A question arose concerning heparin dosage. In 1986, Weiner, C.P. [18] was wondering about the possibility of establishing individual doses based on the assessment of DIC dynamics; the measurement of thrombin markers in plasma was considered (prothrombin fragments F1 + 2, fibrinopeptide A, thrombin-antithrombn complexes, TAT), 
although these markers were as yet to be studied in AFE; finally, he only suggested to use a single intravenous bolus of heparin, 3000 to 5000 units, as soon as the diagnosis was feasible. In 1987, Bonnar (after [11]) advocated a dose of $300-500 \mathrm{U} / \mathrm{h}$. In 1982-84, Uszyński et al. $[19,20]$ administrated heparin intravenously as a bolus $(5000-10,000 \mathrm{U})$ followed by continuous infusion with an intensity warranting the therapeutic level (monitored by aPTT). This therapeutic mode appeared to fit current rules according to which the therapeutic level should be determined using aPTT or heparin assay in plasma [21].

In the years 1969-2011, 208 AFE cases were reported. Heparin (unfractionated heparin) orlow molecular weight heparin (LMWH) was applied in 20 cases $(9.6 \%)$, being the main drug in 11 cases and in 7 casesas a component of spectacular treatment of AFE with cardiac arrest. In the latter group, in 3 cases heparin was used for full heparinization followed by cardiopulmonary bypass, pulmonary artery thromboembolectomy or cardiac thromboembolectomy, and closure of the patent foramen ovale $[3,6,7]$; in 3 other cases heparin was used in the procedure of extracorporeal oxygenation $[8,22,23])$. LMWH was applied in 1 case of atypical AFE (ARDS) [24], and antithrombin with LMWH (danaparoid) in 1 case of AFE with severe uterine hemorrhage [25]. In one case of AFE, heparin was administered in the course of cesarean delivery [20] (Table 1). Moreover, one abstract [26] mentions heparin to be employed together with fibrinogen in 5 of 27 obstetric patients with afibrinogenemia; it is unknown whether there were any cases of AFE among these 5 .

Details concerning women treated with heparin or other anticoagulants are as follows:

In 1969, Maki et al. [17] diagnosed amniotic fluid embolism in a patient in the postpartum period (symptoms appeared $5 \mathrm{~min}$. after placenta expulsion); heparin was used in a single dose of 1500 units (U); soon after injection, relief of dyspnea, clearing of cyanosis and even regression of uterine bleeding were noted.

In 1970, Abbott and Walker [27] began heparin therapy in the early phase of AFE (symptoms of obstetrics shock appeared just before baby delivery), starting from a dose of $10,000 \mathrm{U}$ and continuing with $5000 \mathrm{U}$ every 6 hours for 4 days. The patient survived. Uterine bleeding was considered the effect of DIC.

In 1970, Lyonet et al. [28] diagnosed AFE in a woman who had spontaneous delivery but had to undergo instrumental uterine curettage (placental remnants). Directly after the procedure, symptoms of obstetric shock were noticed, which were not reduced after hydrocortisone injection $(100 \mathrm{mg})$, but improved soon after heparin intravenous administration $(25 \mathrm{mg})$, i.e. cyanosis subsided and blood pressure increased. Heparin therapy was continued for 2 days. No hemorrhagic complications were observed.

In 1973, Chung and Merkatz [29] administered heaprin also in the early phase of AFE. Symptoms of obstetric shock occurred prior to placenta expulsion. Heparin was administered intravenously in a dose of $5000 \mathrm{U}$ every 6 hours for 48 hours; severe consumption coagulopathy was observed. The patient survived.

In the years 1982-84, Uszyński et al. [19,20] applied heparin at the very onset of amniotic fluid embolism in 4 women at labor. In 3 patients, symptoms of amniotic fluid embolism occurred $5-10 \mathrm{~min}$. following placenta expulsion (dyspnea, cyanosis and sudden profound shock without any significant blood loss). In one case, AFE developed at the time of cesarean section carried out in general anesthesia; right after fetus and placenta delivery, there was a sudden drop in blood pressure accompanied by face cyanosis. Gasometry indicated acute hypoxia.

Heparin was a constant component of treatment, which additionally included $100 \%$ concentrated oxygen respiration, application of atropine and Alupent due to bradycardia in one case or lignocaine because of tachycardia in two cases, as well as application of diprophylline and cardiac vera.

In order to achieve effective heparinization in the possibly shortest time, we administered unfractionated heaprin intravenously, first as an injection of $10,000 \mathrm{U}$ (except for cesarean section: $5000 \mathrm{U}$ ), and then as continuous infusion for 2 - 3 days. The infusion rate was regulated based on the measurement of activated partial thromboplastin time (aPTT). We assumed that therapeutic heparinization occurred when aPTT was increased $1.5-2.5$ times (normal value: $40-60 \mathrm{sec}$ ).

When execution of aPTT test was delayed, we measured clotting time of venous blood. Clotting time by the

Table 1. Heparin and other anticoagulants in the treatment of amniotic fluid embolism (AFE).

\begin{tabular}{|c|c|c|c|c|c|}
\hline \multirow[b]{2}{*}{ Period } & \multirow{2}{*}{$\begin{array}{c}\text { Total number of } \\
\text { described cases of AFE }\end{array}$} & \multicolumn{4}{|c|}{ Total number of cases treated with heparin } \\
\hline & & as main drug & $\begin{array}{c}\text { as a component of } \\
\text { spectacular procedures }\end{array}$ & $\begin{array}{l}\text { Low molecular weight } \\
\text { heparin (LMHW) }\end{array}$ & Antithrombin \\
\hline \multirow{2}{*}{$1969-2011$} & 208 & 11 & 7 & 2 & 1 \\
\hline & $(100 \%)$ & $(9.6 \%)$ & & & \\
\hline
\end{tabular}


Lee-White method turned out to be the most useful test early in the treatment, for the physicians in charge could perform it immediately at the patient's bedside (normal value: 4 - $10 \mathrm{~min}$; therapeutic increase: up to $20 \mathrm{~min}$, without, however, going beyond $30 \mathrm{~min}$ ). Moreover, we assessed durability of the clots in test-tubes left at a room temperature (clot observation test).

In 1992, Masson [30] reported the case of atypical AFE in the form of adult respiratory distress syndrome (ARDS). Dramatic respiratory and circulatory disorders appeared 16 hours after labor. Treatment with heparin, antibiotics, furosemide and supplemental oxygen was instituted (no details were provided on heparin therapy). The patient survived.

In 1998, Nishimura et al. [31] described a patient with abruptio placenta who underwent general anesthesia for cesarean section, in which life-threatening intraoperative pulmonary embolism developed (AFE or thromboembolism). After unsuccessful treatment with heparin (5000 $\mathrm{U}$ followed by $5000 \mathrm{U} / \mathrm{h}$ ), recombinant tissue plasminogen activator (rt-PA) was applied. The patient's cardiopulmonary status improved, severe coagulopathy (hemorrhage to the abdominal cavity) was controlled by relaparotomy and substitutive therapy.

In 2003, Huńka et al. [24] diagnosed atypical AFE in the form of ARDS (Adult Respiratory Distress Syndrome) in a 24-year-old female. The authors attributed the patient's cure to low molecular weight heparin (LMWH), although also antibiotics and oxygen therapy were applied.

In 2003, Kent et al. [32] used heparin to treat a parturient at 28 weeks' gestation, with signs and symptoms consistent with AFE including DIC coagulopathy; heaprin was discontinued just before emergency cesarean section and restarted 4 hours after the operation.

In 2011, Hosono et al. [25] described a case of AFE that occurred after complicated vaginal delivery (vacuum extraction-deep vaginal laceration). Dyspnea and hypotension were followed by cardiac arrest, and later severe consumption coagulopathy occurred with uterine hemorrhage, and a temporary intracranial hematoma. In the course of intensive resuscitation, antithrombin (twice 3000 U i.v.) and danaparoid (LMWH; once 1250 U s.c.) were applied and the bleeding was stopped. The patient was rescued.

\subsection{Heparinization Preceding the Surgical Treatment of AFE and Other Procedures}

Three cases of AFE with cardiopulmonary collapse were treated by cardiopulmonary bypass surgery preceded by i.v. injection of a large heparin dose, 30,000 U, for "full heparinization".

In 1990, Esposito et al. [7] described amniotic fluid embolism in a patient after cesarean section. One hour postpartum the patient sustained a sudden cardiac arrest, which was caused, as it turned out later, by particularly dangerous form of AFE (see below). Since resuscitation with closed cardiac massage and assisted ventilation was ineffective, after full heparinization cardiopulmonary bypass and pulmonary artery thromboembolectomy were successfully applied. Massive amount of fetal squames in a removed thrombus was taken as a diagnostic and diffe rential argument: AFE and not pulmonary thromboembolism was diagnosed.

In 2003, Stanten et al. [6] described management of amniotic fluid embolism with cardiac arrest. The complication was caused by catastrophically severe pulmonary vasoconstriction that was revealed by transesophageal echocardiogram examination. When the standard emergency management was ineffective, full heparinization was introduced (30,000 U of heparin), followed by cardiopulmonary bypass. Effective cardiac action was restored after over an hour and then heparinemia was eliminated by protamine sulfate, and the treatment of severe consumption coagulopathy was started. Epinephrine, steroids in high doses and heparin were called life-saving drugs by the authors.

In 2010, Lee et al. [5] treated paradoxical AFE with cardiopulmonary bypass, cardiac thromboembolectomy, and closure of the patent foramen ovale.

There are at least three reports on the successful application of extracorporeal membrane oxygenation (ECMO) in the treatment of AFE $[8,22,23]$. ECMO can mitigate cardiopulmonary collapse filling the role of the obstructed heart and plugged lung. The main lifesaving role can be ascribed to the action of heparin and oxygenation. Early application of ECMO is recommended.

In the commentary to the recalled casuistic cases:

Positive opinions stated on heparin usefulness in AFE seem to be in contrast to reality. The number of AFE cases in which heparin was used is surprisingly small as compared to the total number of reported AFE cases $(20$ vs 208).

First attempts to treat AFE with heparin are errorburdened, e.g. lack of laboratory control of the therapeutic level of heparin in plasma.

\section{RECOMMENDED MODEL OF HEPARIN THERAPY THAT SHOULD BE IMPLEMENTED IN THE RESUSCITATION PROCESS OF AFE}

1) Apply heparin at the very onset of AFE;

2) Quickly obtain the therapeutic level of heparinemia via i.v. injection of $10,000 \mathrm{U}$;

3) Maintain therapeutic level through continuous infusion;

4) Monitor heparinemia using aPTT or heparin assay (aPTT values that are 2.0 to 3.5 times the control 
yield therapeutic heparin levels; heparin levels of 0.3 to 0.7 international units $/ \mathrm{ml}$ form a range of the therapeutic level [21]);

5) Discontinue infusion of heparin after obtaining respiratory and circulatory stability, but then continue LMWH for 7 days (prophylaxis);

6) Never commence heparin therapy in the hemorrhagic phase, instead of considering the use of aprotonin (a loading dose of 2 million IU followed by a continuous infusion of 500,000 IU/hour [33]); a good hemostatic effect was observed after AT and danaparoid [25];

7) Be aware of side effects of heparin: a/ rapid offset of heparin action can be obtained by injecting i.v. protamine sulfate, if needed (proportions: $1 \mathrm{mg}$ of protamine sulfate neutralizes $100 \mathrm{U}$ heparin [34], b/ screen the platelet count followed 2 to 3 times per week for possible heparin induced thrombocytopenia (HIT) [35];

8) Consider the usefulness of extracorporeal membrane oxygenation (ECMO), which comprises the merits of both heparin and oxygen therapy [8,22,23].

\section{REFERENCES}

[1] Abenhaim, H.A., Azoulay, L., Kramer, M.S. and Leduc, L. (2008) Incidence and risk factors of amniotic fluid embolismus: A population-based study on 3 million births in the United States. American Journal of Obstetrics \& Gynecology, 199, 49e1-49e8.

[2] Shechtman, M., Ziser, A., Markovits, R. and Rosenberg, B. (1999) Amniotic fluid embolism: Early findings of transesophageal echocardiography. Anesthesia \& Analgesia, 89, 1456-1458.

[3] Stanten, R.D., Iverson, I.G., Daugharty, T.M., Lovett, S.M., Terrt, C. and Blumenstock, E. (2003) Amniotic fluid embolism causing catastrophic pulmonary vasoconstriction: Diagnosis by echocardiogram and treatment by cardiopulmonary bypass. Obstetrics \& Gynecology, 102, 496-498. doi:10.1016/S0029-7844(03)00161-3

[4] James, C.F., Feinglass, N.G., Menke, D.M., Grinton, S.F. and Papadimos, T.J. (2004) Massive amniotic fluid embolism: Diagnosis aided by emergency transesophageal echocardiography. International Journal of Obstetric Anesthesia, 13, 279-283. doi:10.1016/i.ijoa.2004.03.008

[5] Kumar, V., Khatwani, M., Aneja, S. and Kapur, K.K. (2010) Paradoxical amniotic fluid embolism presenting before caesarean section in a women with an atrial septal defect. International Journal of Obstetric Anesthesia, 19, 94-98. doi:10.1016/j.ijoa.2009.02.014

[6] Lee, P.H.U., Shulman, M.S., Vellayappan, U., Symes, J.F. and Ollenchock Jr., S.A (2010) Surgical treatment of an amniotic fluid embolism with cardiopulmonary collapse. The Annals of Thoracic Surgery, 90, 1694-1696. doi:10.1016/j.athoracsur.2010.05.017

[7] Esposito, R.A., Grossi, E.A., Coppa, G., Gianola, G., Fer- ri, D.P., Angelides, E.M. and Andriakos, P. (1990) Successful treatment of shock caused by amniotic fluid embolism with cardiopulmonary bypass and pulmonary artery thromboembolectomy. American Journal of Obstetrics \& Gynecology, 163, 572-574. doi:10.1016/0002-9378(90)91200-V

[8] Ho, C.-H., Chen, K.-B., Liu, S.-K., Liu, Y.-F., Cheng, H.-C. and Wu, R.-C. (2009) Early application of extracorporeal membrane oxygenation in a patient with amniotic fluid embolism. Acta Anaesthesiologica Taiwanica, 47, 99-102. doi:10.1016/S1875-4597(09)60033-3

[9] Mc Donnell, N.J., Chan, B.O. and Frengley, R.W. (2007) Rapid reversal of critical haemodynamic compromise with nitric oxide in parturient with amniotic fluid embolism. International Journal of Obstetric Anesthesia, 16, 269-273. doi:10.1016/j.ijoa.2006.10.008

[10] Gist, R.S., Stafford, I.P., Leibowitz, A.B. and Beilin, Y. (2009) Amniotic fluid embolism. Anesthesia \& Analgesia, 108, 1599-1602. doi:10.1213/ane.0b013e31819e43a4

[11] Brandjes, D.P.M., Schenk, B.E., Buller, H.R. and Ten Cate, J.W. (1991) Management of disseminated intravascular coagulation in obstetrics. The European Journal of Obstetrics \& Gynecology and Reproductive Biology, 42, S87-S89.

[12] Uszyński, M. (2011) Amniotic fluid embolism: Literature review and integrated concept of pathomechanism. Open Journal of Obstetrics and Gynecology, 1, 178-183. doi:10.4236/ojog.2011.14034

[13] Haas, S. (2008) New oral Xa and IIa inhibitors: Updates on clinical trial results. Journal of Thrombosis and Thrombolysis, 25, 52-60. doi:10.1007/s11239-007-0108-7

[14] Gei, A. and Hankins, G.D.V. (2000) Amniotic fluid embolism: An update. Contemporary OB/GYN, 53, 53-64.

[15] Steiner, P.E. and Lushbaugh, C.C. (1941) Maternal pulmonary embolism by amniotic fluid as a cause of obstetric shock and unexpected deaths in obstetrics. The Journal of the American Medical Association, 117, 12451254. doi:10.1001/jama.1941.02820410023008

[16] Reid, D.E., Weiner, A.E. and Roby, C.C. (1953) Intravascular clotting and afibrinogenemia, the presumptive lethal factors in the syndrome of amniotic fluid embolism. American Journal of Obstetrics \& Gynecology, 66, 465474.

[17] Maki, M., Tachita, K., Kawasaki, Y. and Nagasawa, K. (1969) Heparin treatment of amniotic fluid embolism. The Tohoku Journal of Experimental Medicine, 97, 155160. doi:10.1620/tjem.97.155

[18] Weiner, C.P. (1986) The obstetric patient and disseminated intravascular coagulation. Clinics in Perinatology, 13, 705-717.

[19] Uszyński, M. (1984) Heparin therapy in the primary phase of amniotic fluid embolism. Thrombosis and Haemostasis, 52, 362.

[20] Uszyński, M., Biłyk, B., Jesionowski, Z., Uszyński, W. and Koperski, M. (1984) A favourable result of heparin administration in two cases of clinically diagnosed amniotic fluid embolism (in Polish). Ginekologia Polska, 55, 
625-630.

[21] Weitz, D.S. and Weitz, J.I. (2010) Update on heparin: What do we need to know? Journal of Thrombosis and Thrombolysis, 29, 199-207. doi:10.1007/s11239-009-0411-6

[22] Reyftmann, L., Morau, E., Dechaud, M., Frapier, J.M. and Hedon, B. (2006) Extracorporeal membrane oxygenation therapy for circulatory arrest due to postpartum haemorrhage. Obstetrics \& Gynecology, 107, 511-514. doi:10.1097/01.AOG.0000173970.67736.92

[23] Hesieh, Y.-Y., Chang, C.-C., Li, P.-C., Tsai, H.-D. and Tsai, C.-H. (2000) Successful placation of extracorporeal membrane oxygenation and intra-aortic balloon counterpulsation as lifesaving therapy for a patient with amniotic fluid embolism. American Journal of Obstetrics \& Gynecology, 183, 496-497. doi:10.1067/mob.2000.104834

[24] Huńka, I., Pożoga, J., Popielarz-Grygalewicz, A., Kotlarska, J. and Dąbrowski, M. (2003) Amniotic fluid embolism in a24-year-oldfemale after caesarean section-A case report (in Polish). Kardiologia Polska, 59, 325-327.

[25] Hosono, K., Matsumura, N., Matsuda, N., Fujiwara, H., Sato, Y. and Konishi, I. (2011) Successful recovery from delayed amniotic fluid embolism with prolonged cardiac resuscitation. Journal of Obstetrics and Gynaecology Research, 37, 1122-1125. doi:10.1111/j.1447-0756.2010.01470.x

[26] Liang, B.L. and Hong, D.H. (1992) Diagnosis and management of obstetric acute disseminated intravascular coagulation (in Chinese). Zhonghua Fu Chan Ke Za Zhi, 27, 147-148, 188.

[27] Abbott, P.D. and Walker, C.B.H. (1970) Amniotic fluid embolism: A syndrome of intravascular coagulation. Southern Medical Journal, 63, 1357-1360.
[28] Chung, A.F. and Merkatz, I.R. (1973) Survival following amniotic fluid embolism with early heparinisation. $\mathrm{Ob}$ stetrics \& Gynecology, 42, 809-814.

[29] Lyonnet, M.M., Saint-Arroman, J. and Banssillon, V. (1970) Un cas probable d'embolie amniotique. Guerison parl'heparinotherapie et l'epuration extra-renale. Bulletin de la Fédération des Sociétés de Gynécologie et Dóbstétrique de Langue Française, 22, 66.

[30] Masson, R.G. (1992) Amniotic fluid embolism. Clinics in Chest Medicine, 13, 657-665.

[31] Nishimura, K., Kawaguchi, M., Shimokawa, M., Kitaguchi, K. and Furuya, H. (1998) Treatment of pulmonary embolism during cesarean section with recombinant tissue plasminogen activator. Anesthesiology, 89, 10271028. doi:10.1097/00000542-199810000-00030

[32] Kent, K.J., Cooper, B.C., Thomas, K.W. and Zlatnik, F.J. (2003) Presumed antepartum amniotic fluid embolism. Obstetrics \& Gynecology, 102, 493-495. doi:10.1016/S0029-7844(03)00630-6

[33] Stroup, J.S., Haraway, G.D. and Beal, J.M. (2006) Aprotonin in the management of coagulopathy associated with amniotic fluid embolus. Pharmacotherapy, 26, 689-693. doi:10.1592/phco.26.5.689

[34] Chatelain, S.M. and Quirk Jr., J.G. (1990) Amniotic and thromboembolism. Clinical Obstetrics and Gynecology, 33, 473-481. doi:10.1097/00003081-199009000-00013

[35] Douketis, J.D., Berger, P.B., Dunn, A.S., Jaffer, A.K., Spyropoulos, A.C., Becker, E.C. and Ansell, J. (2008) The perioperative management of antithrombotic therapy: American College of Chest Physicians Evidence-Based Clinical Practice Guidelines (8th Edition). Chest, 133, 299S-339S. 